\title{
AXILLARY ANEURYSM CURED BY LIGATURE OF THE THIRD STAGE OF THE SUBCLAVIAN ARTERY.
}

By FRANCIS T. HEUSTON, M.D., F.R.C.S.; Senior Surgeon to the Adelaide Hospital.

[Read in the Section of Surgery, March 30, 1900.]

Mr. Francis T. Hecstor stated that, having shown a case of traumatic aneurysm, subclavio-axillary, cured by ligature of the left subclavian artery in its third stage, at the last clinical meeting of the Surgical Section, he thought it would be of interest to exhibit a case of idiopathic axillary aneurysm caused by ligature of the right subclavian artery in its third stage.

The patient, a car-driver, aged forty-three, was admitted in to the Adelaide Hospital on January 2nd, 1900. In June, 1898 , he felt a pain of constant character in his right shoulder, which, with swelling of his arm, caused him to apply for relief at a hospital in this city, where his case was diagnosticated as axillary aneurysm. He was admitted in November, 1898, and was treated by instrumental pressure until March, 1899, when he left, somewhat relieved, to resume his work, but, finding the exposure incidental to his employment was giving rise to swelling of his hand and arm, with increased pain, he presented himself for treatment at the Adelaide Hospital. On admission, Mr. Heuston found the patient a strong, muscular, well-nourished man. Immediately beneath his right clavicle a considerable swelling existed, which occupied this region to the lower border of the great pectoral muscle. This tumour had a well-marked distensile pulsation, and on palpation gave the sensation as if a very thin wall existed; in fact, it felt as if it must soon burst. On auscultation, a 
well-marked bmizt was present. On pressure on the shoulder the bruit and pulsation stopped, as did also the radial pulse. On January 11th, 1900, he ligatured the right subclavian artery in its third stage by the usual incision parallel to the clavicle. Considerable enlargement of deep veins and the presence of the lower cord of the brachial plexus in front of the artery gave some trouble in passing the ligature. When the artery was exposed, its coats were found to be remarkably attenuated, so much so as to feel more like the coats of a vein than an artery. Owing to this condition the ligature (strong catgut) was only drawn sufficiently tight to occlude the lumen of the artery, as Mr. Heuston feared its cutting through if pressure was applied. After the operation the progress to recovery was uninterrupted, the wound healing by first intention. The patient left the hospital on January 31 st, 20 days after operation.

On examining the patient now, some 12 weeks after the operation, a solid tumour would be found in the axilla without bmit or pulsation. It would also be noticed that no radial pulse exists in the right arm; no swelling or œdema of the hand or arm is present. The patient had perfect use of his arm, and said he had had no pain since the operation; so it might be claimed that his aneurysm was cured.

September 17th, 1900.-I have seen this patient frequently since operation. $\mathrm{He}$ is following his employment as a cardriver, and has no evidence of his affection returning.

Mr. BenNetr said the sounds audible in the tumour were of such a nature that if heard behind the sternum the question would at once arise whether the man had not aortic aneurysm.

Dr. Dorle said he felt what he thought was pulsation in the tumour. He did not hear any murmur. He believed the impulse was not in the tumour itself, but came from some of the ressels behind it which had undergone compensatory enlargement. 
Mr. Lentaigne congratulated Mr. Heuston on the result obtained. He could hear no heart sounds or murmur of any kind orer the tumour.

DR. KNotT asked if the man was suffering now, or had suffered previously, from albuminuria?

Dr. Gooldivg asked if there was a history of syphilis in the sase?

Dr. Travers Surth said he conld not hear the heart sounds orer the tumour. On listening towards the edge the pulsation of the carotid could be heard.

Mr. JoHnston asked what was the thickness of the catgut used, and was more than a single strand employed? He was glad Mr. Heuston approved of simply approximating the coats of the artery.

Mr. Hetston, in reply, said he was unable to detect any sound over the tumour. As to the condition of the kidneys before eperation, the urine was found to be of sp. gr. 1026, acid reaction, po albumen, no sugar, or deposit. There was no history of syphilis. The catgut used was the thickest variety ordinarily employed in bospital operations. He did not rupture the internal and middle eats because the wall of the artery was too thin. Although it was now laid down that there was no necessity to rupture these coats, still he felt easier in his own mind by rupturing them where admissible. 